\title{
Effects of early versus delayed umbilical cord clamping during antepartum lower segment caesarean section on placental delivery and postoperative haemorrhage: a randomised controlled trial
}

\author{
M Withanathantrige ${ }^{1}$, I M R Goonewardene ${ }^{1}$ \\ (Index words: cesarean section, delayed clamping, umbilical cord, postoperative hemorrhage)
}

\begin{abstract}
Introduction Although recommended, delayed cord clamping (DCC) is not frequently practised during lower segment caesarean section (LSCS).

Objective To assess the effects of DCC during antepartum LSCS on placental delivery and postoperative hemorrhage.

Methods A randomised controlled trial was carried out on 156 women undergoing antepartum LSCS between 37-39 weeks gestation at the Academic Obstetric Unit, Teaching Hospital Mahamodara, Galle from 21 st January to 30th April 2013. One surgeon carried out the LSCS and the same operative technique was used on all. The umbilical cord of the baby was clamped at $<15$ seconds $(n=52)$ or between 60 - 75 seconds $(n=52)$ or between 120 - 135 seconds $(n=52)$ according to a predetermined randomised allocation sequence. Postoperative hemorrhage, time taken for delivery of placenta, requirement of manual removal of placenta and additional uterotonics, and reduction of maternal haemoglobin and haemotocrit 48 - 60 hours after LSCS, were measured. The neonate was monitored for 72 hours.

Results There were no significant differences in postoperative haemorrhage or neonatal morbidity between the groups. There was a clinically non-significant increase in the time taken for placental delivery. The trend of reduction in the need for manual removal of placentae and additional uterotonics with DCC was not significant. The trend of increased requirement of phototherapy for neonatal jaundice with DCC was not significant.

Conclusion There were no significant differences in the risk of postoperative haemorrhage, manual removal of placenta, or maternal or neonatal morbidity between early cord clamping and DCC during antepartum LSCS.
\end{abstract}

\section{Introduction}

Delayed cord clamping (DCC), an inexpensive method which allows physiological placental transfusion has been described since the 1950s [1,2]. DCC is associated with increased birth weight, (mean difference 101g; 95\% CI 45-157), increased new born haemoglobin (mean difference $2.2 \mathrm{~g} / \mathrm{dl} ; 95 \%$ CI 0.3-4.0 g/dl), increased new born haematocrit $>45 \%$ (RR 16.2; 95\% CI 2-127.4) persisting up to 48 hours, and a reduction of the risk of iron deficiency at three to six months of age (RR 2.7; 95\% CI 1.0-6.7) [3]. The requirement of phototherapy for neonatal jaundice is reduced by early cord clamping (RR 0. 62; 95\% CI 0.41-0.96) compared to DCC [3]. However DCC is not associated with lower Apgar Scores at 5 minutes, increased admission to special care baby units, respiratory distress, severe jaundice or long term adverse effects [3-7]. DCC is also not associated with increased risk of postpartum haemorrhage, blood transfusion, manual removal of placenta or increased duration of third stage of labour [3, 6-8]. DCC improves blood pressure, reduces the need for blood transfusions and the risk of intra-ventricular haemorrhage and necrotizing enterocolitis in preterm infants [9]. Furthermore, DCC maintains oxygenation by sustained placental circulation and is beneficial if spontaneous pulmonary respiration is delayed or impaired [10-13]. Recently the use of the term 'deferred' cord clamping has been recommended as this suggests a planned policy in contrast to the term 'delayed' cord clamping which may imply that the cord is clamped later than the ideal time [14].

Although evidence based guidelines have recommended that DCC should be practiced for all births, in

Ceylon Medical Journal 2017; 62: 5-11

DOI: http://doi.org/10.4038/cmj.v62i1.8425

${ }^{1}$ Academic Obstetrics and Gynaecology Unit, Teaching Hospital, Mahamodara, Galle, Sri Lanka.

Correspondence: MG, e-mail:<malikg@eureka.Ik>. Received 2 June 2016 and revised version accepted 10 September 2016. 
many units it is practiced during vaginal deliveries but not during caesarean sections (CS) [15]. This is because most of the data regarding DCC has been obtained from vaginal deliveries and there is a fear of possible increased post-operative hemorrhage after DCC during CS. In the latest Cochrane Review on the subject, out of 15 randomised controlled trials involving 3911 women from 12 countries, only three studies included women who were delivered by CS [3]. Of these three studies, one study carried out in Argentina had 79 out of the 276 women delivered by CS [16]. The other two studies had very few delivering by CS [5,17]. Therefore the objective of this study was to assess the effects of DCC during ante partum LSCS on placental delivery, post-operative haemorrhage and neonatal complications.

\section{Methods}

A randomised controlled trial was conducted on 156 consecutive women with intact membranes and healthy foetuses, who underwent antepartum LSCS between 3739 weeks gestation at the Academic Obstetric Unit, Teaching Hospital, Mahamodara, Galle, Sri Lanka, from $21^{\text {st }}$ January to $30^{\text {th }}$ April 2013. Exclusion criteria were women with increased risk of feto-maternal haemorrhage or post-operative haemorrhage, rhesus negative, multiple pregnancies, estimated fetal weight $>3.5 \mathrm{~kg}$, polyhy-dramnios, blood pressure $>160 / 110 \mathrm{mmHg}$, placenta praevia, abruptio placentae, pre-labor rupture of mem-branes and failed induction of labor. In Sri Lanka, the mean birth weight of a neonate at 40 weeks of gestation and the $90^{\text {th }}$ centile are estimated to be approximately $3 \mathrm{~kg}$ and $3.5 \mathrm{~kg}$ respectively [18]. Audits carried out in the unit have indicated that neonatal birth weight of $>3.5 \mathrm{~kg}$ and induction of labor have increased risks of postpartum haemorrhage (PPH).

The average post-operative blood loss after LSCS is estimated to range from $400-1000 \mathrm{ml}$ and its variance is estimated to be approximately $500 \mathrm{ml}$ [19-21]. To detect an increase of $300 \mathrm{ml}$ or more blood loss after DCC, with $80 \%$ power and $95 \%$ significance, the minimum sample size was calculated as 43.5 per arm for a three arm randomised controlled trial [22]. Using computer generated random numbers and blocks of three (each block including groups 1, 2 and 3 in a random sequence), the second author prepared sequentially numbered and sealed opaque envelopes containing the code for the appropriate umbilical cord clamping regimen. The first author assessed all women admitted to hospital for scheduled (category 3 ) or elective (category 4) CS and obtained informed written consent from those eligible for inclusion. All the participants had their body mass index (BMI) documented on admission to the unit for CS. Just prior to the CS, the on call senior house officer opened the sealed opaque envelopes and assigned the participants to the appropriate umbilical cord clamping regimen and informed the first author. Fifty two subjects were recruited to each arm, ie. a total of 156 to allow for post randomisation exclusions (Figure $1)$.

Lower segment CS (LSCS) was carried out by the first author and the same routine operative techniques were used on all. The preoperative haemoglobin concentration $(\mathrm{Hb})$ and the haematocrit of the mother were measured using a sample of blood obtained when inserting the intravenous cannula prior to CS. Preloading with $500 \mathrm{ml}$ of normal saline was carried out by the anaesthesiologist prior to spinal anesthesia. An intravenous bolus dose of oxytocin $10 \mathrm{iu}$ was administered to the mother following delivery of the baby. This was followed by an infusion of 10 iu oxytocin in $500 \mathrm{ml}$ of normal saline over four hours. Additional doses of uterotonics were given only if there was significant bleeding.

The umbilical cord of the baby was clamped at $<15$ seconds (Group 1) or between 60-75 seconds (Group 2) or between 120-135 seconds (Group 3,) according to the predetermined randomised allocation sequence. Bleeding from the uterine cut edges were controlled by the routine use of three Green Armitage clamps, two for the lower cut edge and one for the upper cut edge. The baby was covered with a sterile, dry and warm cloth to prevent hypothermia, and placed on the mother's thighs, until the cord was clamped and divided, in the DCC groups. None of the neonates required resuscitation. After clamping the cord, controlled cord traction was applied to deliver the placenta. Time interval from delivery of the baby to the delivery of the placenta was documented. In groups 2 and 3 if the placenta separated before the stipulated time interval for the particular group, it was removed and time of such removal was documented. If there was a delay in placental separation and delivery, controlled cord traction was applied at 30 second intervals up to a maximum of five minutes. If the placenta was not delivered in five minutes, a manual removal of placenta was carried out. The uterine incision was sutured in two layers using No. 1 polyglactin. The visceral peritoneum of the uterus was not sutured.

The postoperative blood loss was calculated in all three arms of the study using the following methods. The surgical sucker was used only when the amniotic membranes were ruptured and up to the delivery of the placenta. Only gauze towels were used to mop up the blood during the balance time of the LSCS, up to closure of the abdomen. The amniotic fluid was carefully sucked into the sucker bottle avoiding spillage onto the gauze towels and the drapes. However some amount of blood mixing up with the liquor being sucked could not be prevented. As soon as the placenta was delivered, the total volume in the sucker bottle was measured by an assistant, the fluid in the sucker bottle was well shaken, and a 10 $\mathrm{ml}$ sample of the fluid was obtained into a BD Vacutainer plastic tube with ethylene diaminetetra acetic acid 
(Becton, Dickinson and Company; Haryana, India). This sample was sent to the laboratory where it was kept at room temperature for 30 minutes and centrifuged at 3500 rpm $(2000 \mathrm{~g})$ for 10 minutes. The volume of blood in the sucker bottle was calculated using the following formula:

Volume of blood in sucker bottle $=$ percentage of packed cells in the $10 \mathrm{ml}$ sample $\times$ total volume in sucker bottle $\div$ preoperative hematocrit

All the towels and drapes prepared for the LSCS were weighed and the weight marked on each pack, prior to autoclaving. All of them (used and unused) were weighed again after use, and a difference of one gram was considered to be equivalent to one $\mathrm{ml}$ of blood. The volume of blood obtained by gravimetry was added to the volume of blood obtained by calculation from the sucker bottle solution to obtain the postoperative blood loss. Birth weights of the neonates were documented and the neonates were kept under close observation by the neonatology team for a minimum of 72 hours. Neonates were monitored for neonatal jaundice. The postoperative $\mathrm{Hb}$ and haematocrit of the mother were measured as per routine 48-60 hours after the CS. The $\mathrm{Hb}$ and haematocrit were measured using a Mindray BC-5800 Haematology Analyser (Mindray, Shenzen, China). The neonatology team was blinded to the timing of the umbilical cord clamping.

Normally distributed continuous variables were described as means and 95\% confidence intervals and compared using ANOVA. Parity was described using medians and inter-quartile ranges and compared using the Mann-Whitney U test. Percentages were compared using Chi-square test. The data was analyzed using an intention to treat analysis. As the variances in the outcome measures were not significantly different between the 60-75 second group and the 120-135 second groups, comparisons were also carried after combining these two groups into one DCC group (60-135 second). A multiple regression analysis was carried out to study the association between mean postoperative blood loss and maternal age, parity, BMI, the number of previous CS, and the birth weight of the neonate, among the three groups. Using a receiver operating characteristics (ROC) curve with a postoperative haemorrhage of $\geq 500 \mathrm{ml}$ as the outcome, optimum cut off levels were obtained for the variables maternal age, BMI, and the birth weight of the neonate. Using these cut off levels, the odds ratios (OR) and their 95\% confidence intervals (95\% CI) were calculated for the occurrence of post-operative haemorrhage of $\geq 500$ $\mathrm{ml}$ with these variables. Analysis of results was carried out using Statistical Package for the Social Sciences (SPSS version 20).

Approval was obtained from the Ethical Review Committee, Faculty of Medicine, University of Ruhuna, Galle (3.7, 26 / 07 / 2012). Informed written consent was obtained from all participants. The study was registered in the Sri Lanka Clinical Trials Registry (SLCTR / 2013/003 on $20^{\text {th }}$ January 2013, http:// trials.slctr.lk/trials/108).

\section{Results}

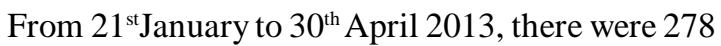
antepartum LSCS and of them 156, (52 for each arm) were recruited for the study. In the DCC groups there was no significant bleeding from the uterine incision which required additional clamps, abandoning the trial or need for early cord clamping. In three cases in the 120-135 second cord clamping group, the placenta separated before the determined time and therefore placenta was removed. An intention to treat analysis was carried out including these three cases (Figure 1).

There were no significant differences in maternal age, parity, gestational age and BMI among the three groups. Majority of the mothers were in the 30-39 years age group and para 2, 3 and 4 (Table 1). There were no significant differences in the mean postoperative blood loss between the three groups or between the early cord clamping ( $<15$ seconds) and the DCC (60-135 seconds) groups. Mean duration for placental delivery increased from 120 seconds (95\% CI 92-148) to 195 seconds (95\% CI 171-218, $p<0.001$ ) but retained placentae were not increased. There were non-significant trends towards a reduced need for a manual removal of the placenta from $11.5 \%$ to $6.7 \%$ and a reduced need for additional uterotonics from $13.5 \%$ to $6.7 \%$ in the early cord clamping group compared to the combined DCC groups. The mean postoperative reductions in $\mathrm{Hb}$ and haematocrit were not significantly different between the three groups. The requirement of phototherapy for neonatal jaundice showed a non-significant increase from $7.7 \%$ in the early cord clamping group to $13.5 \%$ in the combined DCC groups (Table 2).

None of the subjects required colloids or other blood products and none of the neonates had Respiratory Distress Syndrome (RDS) or needed admission to the special care baby unit (SCBU). There were no significant differences in the requirement of additional crystalloids, between the three groups. A postoperative blood loss of $\geq 500 \mathrm{ml}$ occurred in approximately $45 \%$ of the study population ranging from approximately $39 \%$ in the $<15$ seconds cord clamping group to $54 \%$ in the $60-75$ second cord clamping group. However these differences were not statistically significant. The largest blood loss was approximately $856 \mathrm{ml}$. A postoperative blood loss of $\geq 750 \mathrm{ml}$ occurred in approximately $3 \%$ of the study population. None had postoperative blood loss of $\geq 1000 \mathrm{ml}$ (Table 3 ). There were no clinically significant differences in the risk of increased postoperative haemorrhage according to maternal age, parity, BMI, number of previous $\mathrm{CS}$ or the birth weight of the neonate, among the three groups (Table 4). 
Figure 1: Flow Chart of the Method

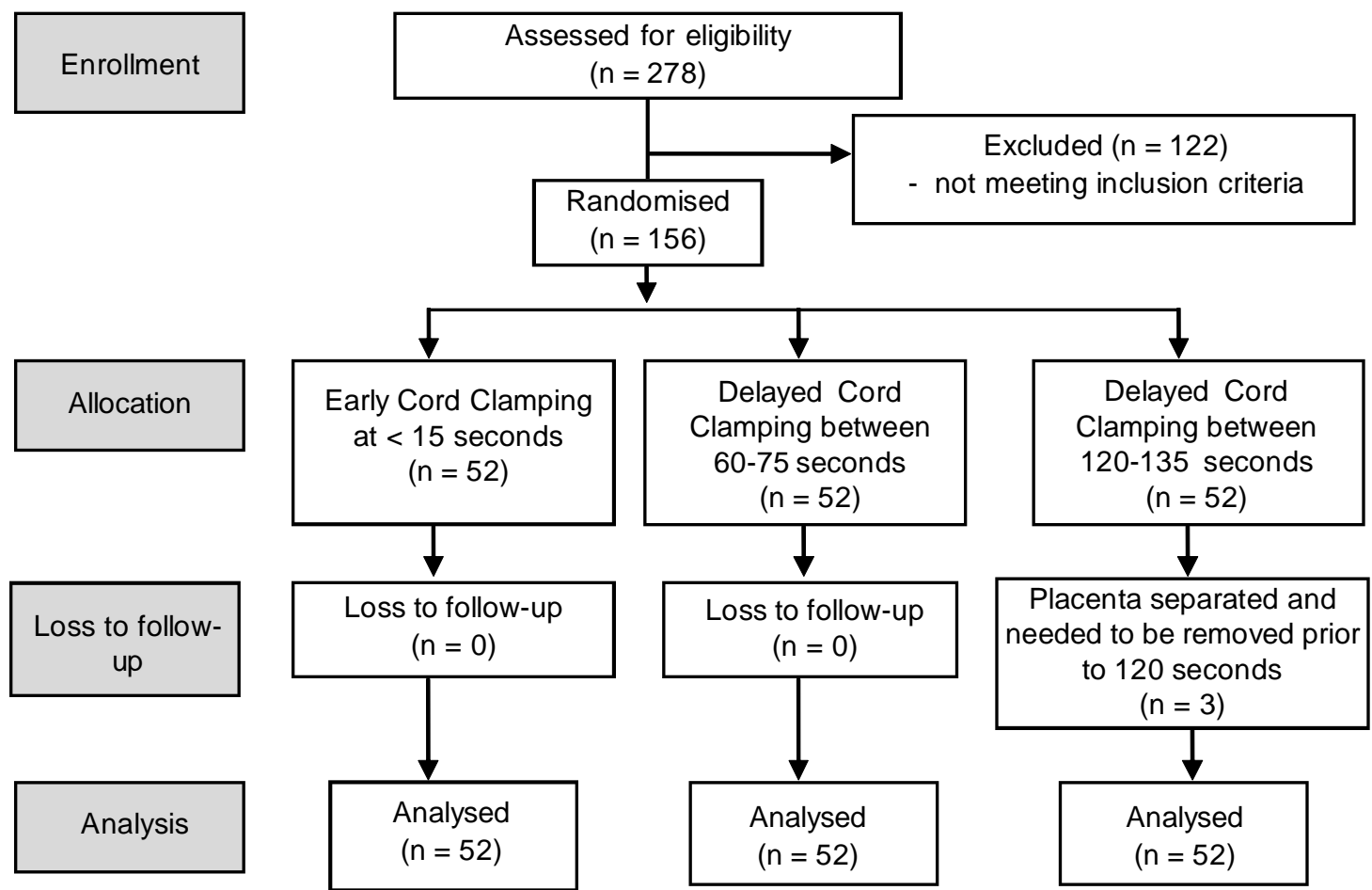

Table 1. Basic characteristics according to the timing of cord clamping $(\mathrm{N}=156)$

\begin{tabular}{|c|c|c|c|c|}
\hline & $\begin{array}{c}<15 \text { seconds group } \\
(n=52)\end{array}$ & $\begin{array}{l}\text { 60-75seconds group } \\
(n=52)\end{array}$ & $\begin{array}{c}120-135 \text { seconds group } \\
(n=52)\end{array}$ & $p$ value \\
\hline Age - years : mean & 32.6 & 30.7 & 30.2 & \\
\hline$(95 \% \mathrm{CI})$ & $(30.8-34.4)$ & $(29.1-32.3)$ & $(28.8-32.6)$ & 0.091 \\
\hline Parity : median & 2 & 2 & 3 & \\
\hline (IQR) & $(2-3)$ & $(2-3)$ & $(2-3)$ & 0.896 \\
\hline GA- weeks : mean & 37.9 & 38 & 37.9 & \\
\hline$(95 \% \mathrm{CI})$ & $(37.6-38.2)$ & $(37.8-38.2)$ & $(37.7-38.1)$ & 0.677 \\
\hline BMI : mean & 25.7 & 24.9 & 25.5 & \\
\hline$(95 \% \mathrm{CI})$ & $(24.8-26.6)$ & $(24.1-25.7)$ & $(24.5-26.5)$ & 0.375 \\
\hline
\end{tabular}

GA=Gestational age $; B M I=$ Body Mass Index;95\% CI=95\% Confidence Interval; $I Q R=$ Inter Quartile Range

ANOVA used for comparisons of mean Age, GA and BMI; Mann Whitney U test used for comparisons of Median parity

Table 2. Main outcomes according to the timing of cord clamping $(\mathbf{N}=156)$

\begin{tabular}{|c|c|c|c|c|}
\hline & $\begin{array}{l}<15 \text { second group } \\
\quad(n=52)\end{array}$ & $\begin{array}{l}60-75 \text { second group } \\
(n=52)\end{array}$ & $\begin{array}{l}\text { 120-135 second group } \\
\quad(n=52)\end{array}$ & $\begin{array}{l}\text { 60-135 second group } \\
(n=104)\end{array}$ \\
\hline Operative blood loss in ml: & 492 & 523 & 493 & 508 \\
\hline mean $(95 \% \mathrm{CI})$ & $(462-522)$ & $(488-558)$ & $(455-531)$ & $(471-537)$ \\
\hline $\begin{array}{l}\text { Time duration for placental delivery } \\
\text { in seconds: mean }(95 \% \mathrm{CI})\end{array}$ & $\begin{array}{c}120 \\
(92-148)\end{array}$ & $\begin{array}{c}172 \\
(149-195)\end{array}$ & $\begin{array}{c}195 \\
(171-218)\end{array}$ & $\begin{array}{c}184 \\
(153-211)\end{array}$ \\
\hline Need for MRP after 5 minutes (\%) & $6(12 \%)$ & $4(8 \%)$ & $3(6 \%)$ & $7(7 \%)$ \\
\hline Need for additional uterotonics (\%) & $7(13 \%)$ & $4(8 \%)$ & $3(6 \%)$ & $7(7 \%)$ \\
\hline $\begin{array}{l}\text { Post-operative haemoglobin } \\
\text { reduction in g/dl: mean }(95 \% \mathrm{CI})\end{array}$ & $\begin{array}{c}0.4 \\
(0.32-0.48)\end{array}$ & $\begin{array}{c}0.5 \\
(0.35-0.5)\end{array}$ & $\begin{array}{c}0.4 \\
(0.42-0.58)\end{array}$ & $\begin{array}{c}0.4 \\
(0.3-0.5)\end{array}$ \\
\hline $\begin{array}{l}\text { Post-operative haematocrit } \\
\text { reduction (\%): mean }(95 \% \mathrm{CI})\end{array}$ & $\begin{array}{c}0.9 \\
(0.7-1.1)\end{array}$ & $\begin{array}{c}1.1 \\
(0.8-1.4)\end{array}$ & $\begin{array}{c}0.8 \\
(0.6-1.1)\end{array}$ & $\begin{array}{c}1.0 \\
(0.7-1.2)\end{array}$ \\
\hline $\begin{array}{l}\text { Neonatal jaundice requiring } \\
\text { phototherapy }(\%)\end{array}$ & $\begin{array}{c}4 \\
(8 \%)\end{array}$ & $\begin{array}{c}8 \\
(16 \%)\end{array}$ & $\begin{array}{c}6 \\
(12 \%)\end{array}$ & $\begin{array}{c}14 \\
(14 \%)\end{array}$ \\
\hline
\end{tabular}


Table 3. Occurrence and severity of post-operative haemorrhage according to the timing of cord clamping $(\mathrm{N}=156)$

\begin{tabular}{|c|c|c|c|c|}
\hline & $\begin{array}{c}<15 \text { second group } \\
(n=52)\end{array}$ & $\begin{array}{l}60-75 \text { second } \\
\text { group }(n=52)\end{array}$ & $\begin{array}{l}120-135 \text { second } \\
\text { group }(n=52)\end{array}$ & $p$ value \\
\hline Calculated blood loss & 20 & 28 & 22 & \\
\hline$\geq 500 \mathrm{ml}$ & $(39 \%)$ & $(54 \%)$ & $(42 \%)$ & $0.260^{*}$ \\
\hline Calculated blood loss & 12 & 12 & 12 & \\
\hline$\geq 600 \mathrm{ml}$ & $(23 \%)$ & $(23 \%)$ & $(23 \%)$ & $1.000^{*}$ \\
\hline Calculated blood loss & 0 & 2 & 3 & \\
\hline$\geq 750 \mathrm{ml}$ & & $(4 \%)$ & $(6 \%)$ & $0.235^{*}$ \\
\hline
\end{tabular}

* No significant differences with Chi Square Trend

Table 4. Postoperative blood loss according to maternal age, parity, body mass index, number of previous Caesarean sections and birth weight of the baby $(N=156)$

\begin{tabular}{|c|c|c|c|}
\hline & $\begin{array}{l}<15 \text { second group } \\
\quad(n=52)\end{array}$ & $\begin{array}{c}60-75 \text { second group } \\
(n=52)\end{array}$ & $\begin{array}{c}120-135 \text { second group } \\
(n=52)\end{array}$ \\
\hline Maternal Age: & 1.128 & 1.070 & 0.994 \\
\hline \multirow[t]{2}{*}{$\mathrm{OR}(95 \% \mathrm{CI})$} & $(1.008-1.262)$ & $(0.95-1.204)$ & $(0.874-1.132)$ \\
\hline & $p=0.033$ & $p=0.257$ & $p=0.930$ \\
\hline Parity: & 0.744 & 0.469 & 1.919 \\
\hline \multirow[t]{2}{*}{$\mathrm{OR}(95 \% \mathrm{CI})$} & $(0.323-1.714)$ & $(0.152-1.452)$ & $(0.51-7.188)$ \\
\hline & $p=0.487$ & $p=0.189)$ & $p=0.334$ \\
\hline Maternal Body Mass & 0.982 & 1.004 & 1.181 \\
\hline \multirow[t]{2}{*}{ Index: OR (95\% CI) } & (0.806-1.196) & $(0.801-1.258)$ & $(0.949-1.470)$ \\
\hline & $p=0.857$ & $p=0.973$ & $p=0.135$ \\
\hline Number of previous & 0.845 & 1.643 & 0.198 \\
\hline Caesarean Sections: & $(0.304-2.348)$ & $(0.462-5.839)$ & $(0.038-1.021)$ \\
\hline OR $(95 \% \mathrm{CI})$ & $p=0.747$ & $p=0.443$ & $p=0.053$ \\
\hline Birth Weight of Baby: & 1.002 & 1.002 & 1.002 \\
\hline \multirow[t]{2}{*}{$\mathrm{OR}(95 \% \mathrm{CI})$} & $(1.002-1.004)$ & $(1.002-1.004)$ & $(1.002-1.004)$ \\
\hline & $p=0.109$ & $p=0.062$ & $p=0.032$ \\
\hline
\end{tabular}

OR $=$ Odds Ratio; $95 \%$ CI= 95\% Confidence Interval

Table 5. Odds Ratios (and 95\% confidence intervals) for the occurrence of postpartum haemorrhage ( $>500 \mathrm{ml}$ ) according to maternal age, body mass index and birth weight of neonate among the three timings of cord clamping $(N=156)$

\begin{tabular}{lcccc}
\hline & $\begin{array}{c}<15 \\
\text { second group } \\
(n=52)\end{array}$ & $\begin{array}{c}60-75 \\
\text { second group } \\
(n=52)\end{array}$ & $\begin{array}{c}120-135 \\
\text { second group } \\
(n=52)\end{array}$ & $\begin{array}{c}60-135 \\
\text { second group } \\
(n=104)\end{array}$ \\
\hline *Maternal Age> & 2.06 & 2.669 & 1.19 & 1.84 \\
31 years: & $(0.55-7.97)$ & $(0.75-9.72)$ & $(0.33-4.25)$ & $(0.78-4.35)$ \\
OR $(95 \% \mathrm{CI})$ & $p=0.227$ & $p=0.087$ & $p=0.765$ & $p=0.125$ \\
*Maternal BMI> & 0.95 & 2.2 & 3.04 & $(1.01-5.72)$ \\
24.75 Kg / M & $(0.27-3.35)$ & $(0.63-7.89)$ & $(0.81-11.82)$ & $p=0.029$ \\
OR $(95 \% \mathrm{CI})$ & $p=0.930$ & $p=0.163$ & $p=0.061$ & 3.47 \\
*Birth Weight of & 1.44 & 4.09 & 2.77 & $(1.42-8.58)$ \\
neonate $\geq 3 \mathrm{Kg}$ & $(0.39-5.38)$ & $(1.08-16.06)$ & $(0.76-10.4)$ & $p=0.002$ \\
OR $(95 \% \mathrm{CI})$ & $p=0.532$ & $p=0.017$ & $p=0.080$ & \\
\hline
\end{tabular}

* Cut off levels obtained by plotting a Receiver Operating Characteristics curve with a post-operative hemorrhage of $\geq 500 \mathrm{ml} ; \mathrm{BMI}=\mathrm{Body}$ Mass Index. 
The optimum cut off levels for maternal age (31 years), BMI $\left(24.75 \mathrm{Kg} / \mathrm{M}^{2}\right)$ and birth weight of the neonate $(3 \mathrm{Kg})$ were obtained by plotting ROC curves against a post-operative haemorrhage of $\geq 500 \mathrm{ml}$. In the combined DCC groups (60-135 seconds) maternal BMI $\geq 24.75 \mathrm{Kg}$ and birth weight of neonate $\geq 3 \mathrm{Kg}$ were associated with a higher odds of a post-operative haemorrhage of $\geq 500 \mathrm{ml}$ (OR 2.4; 95\% CI 1.01-5.72; $p=0.029$, and OR $3.47 ; 95 \%$ CI 1.42-8.58; $p=0.002$ respectively) (Table5).

\section{Discussion}

DCC during antepartum LSCS was not associated with any significant increase of postoperative haemorrhage when compared with early cord clamping. Although the mean duration for placental delivery was increased in the DCC groups, there was no increase in retained placentae, clinically significant excessive maternal bleeding or neonatal morbidity. As all the participants with a postoperative blood loss of $\geq 500 \mathrm{ml}$ were asymptomatic and haemodynamically stable, and there were no participants with a postoperative blood loss of $\geq 1000 \mathrm{ml}$, none of the participants needed a blood transfusion. A few decades ago drainage of the cord was recommended to facilitate placental separation and expulsion. In the current study there were nonsignificant trends towards reductions in the need for a manual removal of placenta and additional uterotonics in the DCC groups. Further multi-center studies with appropriate sample size may confirm these additional benefits and further strengthen the arguments for DCC during CS. Until the cord is clamped, the baby should be placed on the mother's thighs, wrapped well with sterile, dry cloths to prevent neonatal hypothermia especially in air-conditioned operating theaters.

A strength of the study is that the postoperative blood loss after CS was calculated by the combined method involving direct measurements and weighing, which is considered to be the most accurate practical method [23]. Even with maximum efforts to drain the amniotic fluid into the sucker bottle, there would have been some contamination of towels and drapes, and some evaporation could also have occurred from the soaked towels and drapes, and using a sample of $10 \mathrm{ml}$ to estimate the volume of blood in the sucker bottle solution would have had a margin of error. However, the combined method should be more accurate than visual estimations by the surgeon and anesthesiologists, which are the commoner methods used for estimating postoperative blood loss.

The hematological benefits of DCC to the baby during its infancy, are well documented in studies carried out during vaginal delivery, and there is no reason to doubt that the same benefits would be seen after CS. Therefore haematological studies were not carried out either in the neonate or later during its infancy. As the primary objective of the study was to study whether DCC resulted in a clinically significant difference in postoperative blood loss after CS, in comparison to early cord clamping, the sample size was calculated to detect such a difference and not to study the occurrence of neonatal jaundice requiring phototherapy. Therefore the higher occurrence of neonatal jaundice requiring phototherapy in the DCC groups did not reach statistical significance.

The moderate increase in the risk of a postoperative haemorrhage of $\geq 500 \mathrm{ml}$ in the combined DCC groups with maternal BMI $\geq 24.75 \mathrm{Kg}$ and birth weight of neonate $\geq 3 \mathrm{Kg}$ probably reflects the higher risk of $\mathrm{PPH}$ asso-ciated with increasing maternal $\mathrm{BMI}$ and fetal macro-somia, which has been observed in audits carried out in the unit previously.

In conclusion, DCC during antepartum LSCS is feasible and safe, and there should be no hesitation in implementing this procedure routinely. DCC is not associated with any clinically significant difference in the risk of postoperative haemorrhage, manual removal of placenta, or maternal or neonatal morbidity, compared to early cord clamping. During DCC, the baby should be well wrapped to prevent hypothermia, and placed on the mothers thighs.

\section{Conflicts of interest}

There are no conflicts of interest.

\section{References}

1. McCausland AM, Holmes F, Schumann WR. Management of cord and placental blood and its effect on the newborn. West J Surg Obstet Gynaecol 1950; 58: 591 - 608.

2. Colozzi AE. Clamping of the umbilical cord - its effect on the placental transfusion. N Engl J Med 1954; 250: 629-32.

3. McDonald SJ, Middleton P, Dowswell T, Morris PS. Effect of timing of umbilical cord clamping of term infants on maternal and neonatal outcomes. Cochrane Database Syst Rev 2013. Issue 7. Art No.: CD004074.

4. Hutton EK, Hassan ES. Late vs early clamping of the umbilical cord in full term neonates. Systematic Review and Meta-analysis of Control Trials. JAMA 2007; 297: 1241-52.

5. Andersson O, Hellstrom-Westas L, Andersson D, Domellof M. Effect of delayed versus early umbilical cord clamping on neonatal outcomes and iron status at 4 months: A randomized controlled trial. BMJ 2011; 343: D7157.

6. Abalos E. Effect of timing of umbilical cord clamping of term infants on maternal and neonatal outcomes. RHL Commentary. (last revised: 2 March 2009), The WHO-RHL, Geneva: World Health Organization.

7. Van Rheenen P, Bernard JB. Late umbilical cord clamping as an intervention for reducing iron deficiency anemia in term infants in developing and industrialized countries: a systematic review. Ann Trop Paediatr 2004; 24: 3-16. 
8. World Health Organization. Recommendations for the Prevention of Postpartum Hemorrhage. Geneva: WHO, Geneva 2012.

9. Rabe H, Diaz - Rossello JL, Duley L, Dowswel T. Effect of timing of umbilical cord clamping and other strategies to influence placental transfusion at pre term birth on maternal and infant outcomes. Cochrane Database Syst Rev 2012; 8: CD003248.

10. Yigit MB, Kowalski WJ, Hutchon DJR, Pekkan K. Transition from fetal to neonatal circulation: Modeling the effect of umbilical cord clamping. J Biomech 2015; 48: 1662-70.

11. Polglace GR, Dawson JA, Cluckow M, et al. Ventilation onset prior to umbilical cord clamping (Physiological-based cord clamping). Improves systemic and cerebral oxygenation in preterm lambs. PLOS One, February 17,2015. DOI: 10.1371/ journal.pone.0117504.

12. Neville E, Meyor MP. Effect of delayed cord clamping (DCC) on breathing and transition at birth in very preterm infants. Early Hum Dev 2015; 91: 407-11.

13. Lakshminrusimha $\mathrm{S}$, Neurs KV. Better timing for cord clamping is after onset of lung aeration. Paed Res 2015; 77: 615-7.

14. Royal College of Obstetricians and Gynaecologists. Clamping of the umbilical cord and placental transfusion. Scientific Impact Paper No. 14, RCOG, 2015.

15. World Health Organization. Guideline: Delayed umbilical cord clamping for improving maternal and infant health and nutrition outcomes. WHO, Geneva 2014.

16. Carnadas JMC, Carroli G, Pellegrini L, et al. Effect of timing of cord clamping on neonatal venous hematocrit values and clinical outcome at term. A randomized controlled trial. Paediatrics 2006; 117: 779-86.

17. Nelson NM, Enkin MW, Saigal S, et al. Arandomized clinical trial of the Leboyer approach to child birth. $N$ Engl J Med 1980; 302: 655-60.

18. Shanmugarajah Y, Kumarasiri SG, Wahalawatte SL, et al. Sri Lankan fetal/birthweight charts: validation of global reference for fetal weight and birth weight percentiles. Ceylon Med J 2013; 58: 62-5.

19. Newton M, Mosey IM, Egli GE, et al. Blood loss during an immediately after delivery. Obstet Gynaecol 1961; 17: 9-18.

20. Newton M. Postpatum hemorrhage. Am J Obstet Gynaecol 1966; 94: 711-6.

21. Gahres EE, Albert SN, Dodek SM. Intrapartum blood loss measured with Cr51-tagged erythrocytes. Obstet Gynaecol 1962; 19: 455-62.

22. Kirkwood BR. Essentials of Medical Statistics.1995 Blackwell Science. London. p 191-201.

23. Mavis N, Schorn CNM. Measurement of blood loss: Review of the Literature. J Midwifery Women's Health 2010; 55: 20-7. 